\title{
Comparison of magnetic resonance angiography, duplex ultrasound, and digital subtraction angiography in assessment of extracranial internal carotid artery stenosis
}

\author{
G R Young, P R D Humphrey, M D M Shaw, T E Nixon, E T S Smith
}

\section{Abstract}

The results of a prospective study comparing ultrasound, intra-arterial digital subtraction angiography, and magnetic resonance angiography in the assessment of the degree of extracranial internal carotid artery stenosis are reported in patients with symptoms of recent carotid territory ischaemia. A total of 70 patients and 137 vessels were examined by all three techniques. The results obtained by each technique were reported blind. The mean difference (SD) for the comparison of magnetic resonance angiography and digital subtraction angiography was -0.7 (14)\%, for ultrasound and digital subtraction angiography 3.1 (15)\%, and for magnetic resonance angiography and ultrasound $-3.8(15) \%$. The level of agreement was greater for the more tightly stenosed vessels. With the assumption that the results of the digital subtraction angiogram reflect the true situation, the sensitivity and specificity in the detection of $\geqslant 30 \%$ stenoses were $93 \%$ and $82 \%$ with ultrasound and $89 \%$ and $82 \%$ with magnetic resonance angiography; for stenoses $\geqslant 70 \% 93 \%$ and $92 \%$ with ultrasound and $90 \%$ and $95 \%$ with magnetic resonance angiography; and for stenoses of $70-99 \% 89 \%$ and $93 \%$ with ultrasound and $86 \%$ and $93 \%$ with magnetic resonance angiography. For occlusion the values were $93 \%$ and $99 \%$ with ultrasound and $80 \%$ and $99 \%$ with magnetic resonance angiography. Increased sensitivity and specificity were obtained when analysis was confined to those vessels in which ultrasound and magnetic resonance angiography were in agreement over classification. It is thus possible to accurately categorise the degree of stenosis of the extracranial internal carotid artery from a combination of ultrasound and magnetic resonance angiography. The adoption of this combination for the investigation of patients before carotid endarterectomy removes the risk associated with conventional angiography and represents an important advance in the management of carotid stenosis.

\section{$(\mathcal{F}$ Neurol Neurosurg Psychiatry 1994;57:1466-1478)}

The European Carotid Surgery Trial (ECST) and the North American Symptomatic Carotid Endarterectomy Trial (NASCET) have shown the benefit of carotid endarterectomy over current best medical care for patients with high grade stenosis of the symptomatic internal carotid artery. ${ }^{12}$ In such patients, after carotid endarterectomy, the risk of disabling stroke or death is reduced by about $75 \%$. This benefit exists only if the risk of stroke or death during investigation and operation is low. If this risk exceeds $10 \%$, the value of operation is marginal.

Adequately displaying the appropriate carotid artery and accurately defining any stenosis present therefore plays a vital part in the management of patients with presumed ischaemic events in the territory of the carotid artery. The two techniques routinely employed for this purpose are duplex ultrasound examination and $x$ ray contrast angiography. Whereas some centres routinely perform carotid endarterectomy on the basis of results from duplex ultrasound alone, ${ }^{3-6}$ most surgeons in the United Kingdom require angiographic demonstration of the carotid bifurcation, by either conventional cerebral angiography or intra-arterial digital subtraction angiography, before proceeding to operate. ${ }^{7}$ Unfortunately, for this group of patients these invasive techniques carry a risk of causing stroke of between $1 \%$ and $4 \% .{ }^{8}$ This risk seems to be greater for those patients in whom there is appreciable atherosclerotic narrowing of the carotid artery. Our own series shows a $2 \%$ risk of serious stroke for patients with more than $30 \%$ stenosis of the carotid artery undergoing selective intra-arterial digital subtraction angiography. ${ }^{9}$ The risks of angiography should be added to those of operation when considering patients for endarterectomy. Therefore, while striving to reduce surgical risks, every effort must also be made to reduce the risks of angiography during the preoperative assessment of these patients. Magnetic resonance angiography is a new technique that can produce angiograms noninvasively (fig 1 ). In a prospective study, we set out to measure the level of agreement between magnetic resonance angiography, intra-arterial digital subtraction angiography, and duplex ultrasound in determining the degree of stenosis of the internal carotid artery, at or around the carotid bifurcation, in patients under consideration for prophylactic carotid endarterectomy.

\section{Methods}

The study involved consecutive patients referred to the Walton Centre for Neurology 


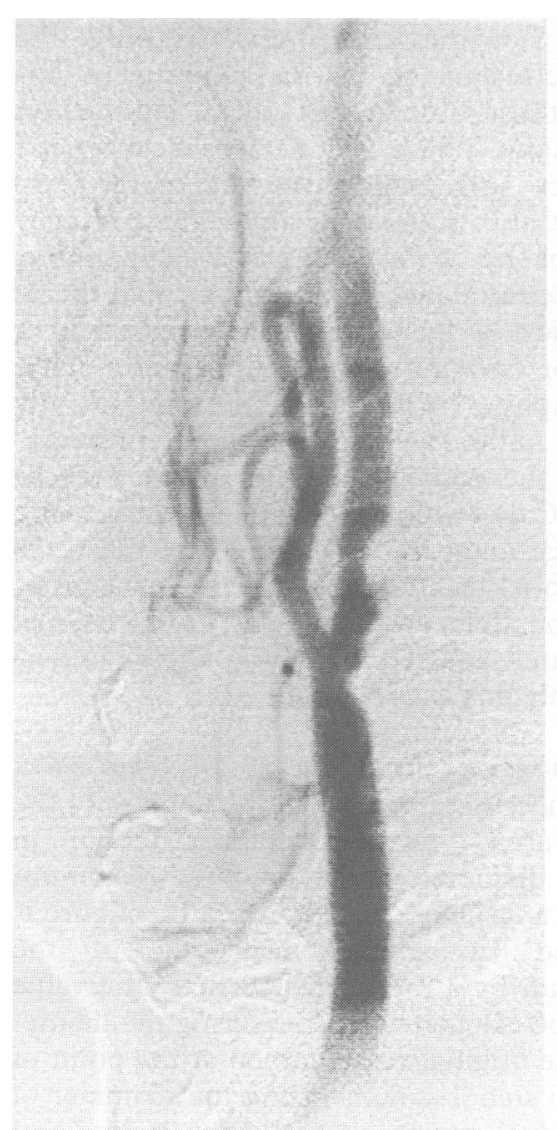

A
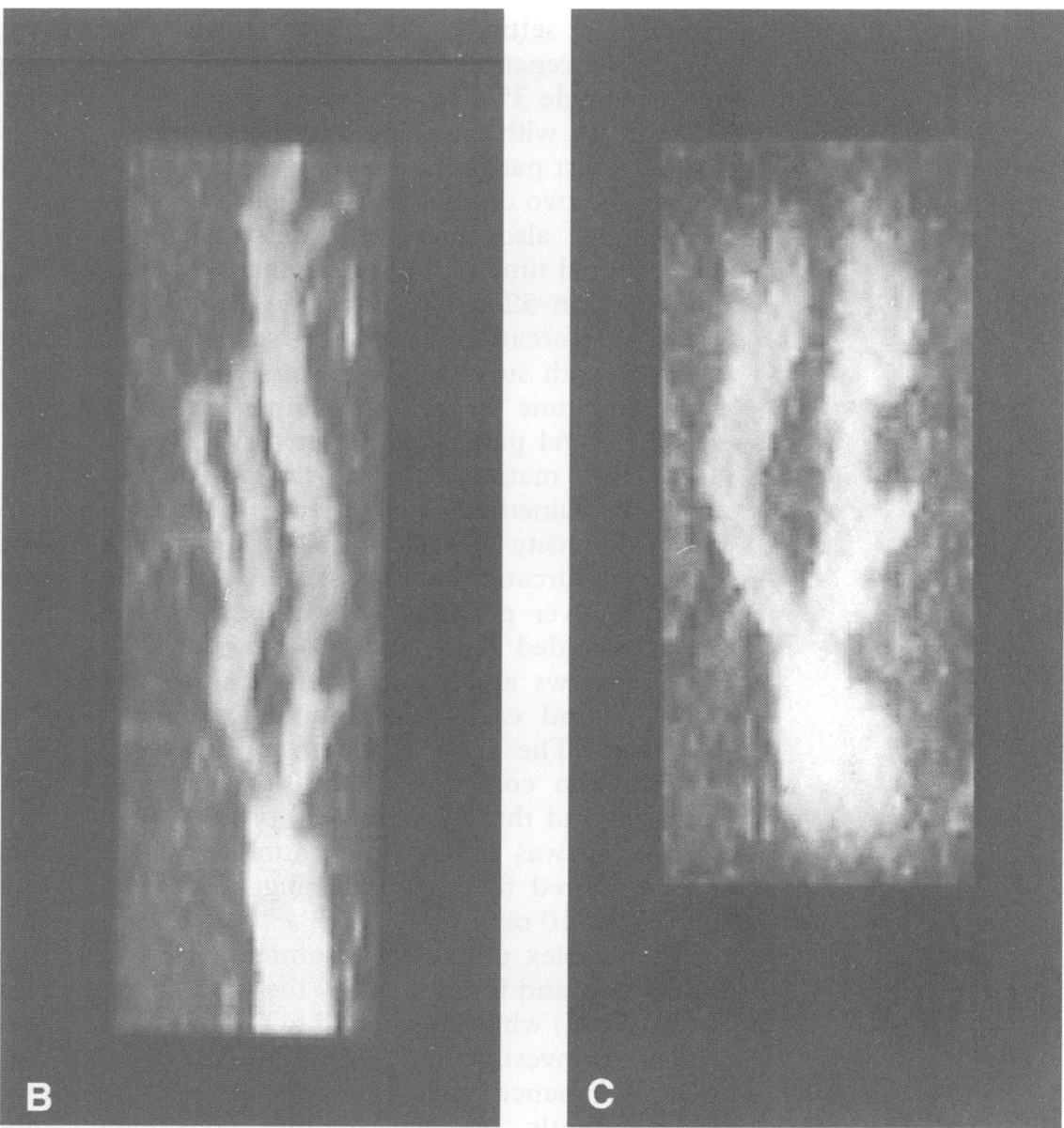

Figure 1 (A) Intra-arterial digital subtraction angiogram showing ulcerated, irregular stenosis of distal common and proximal internal carotid artery with $(B)$ corresponding two dimensional, and $(C)$ three dimensional magnetic resonance angiogram.

and Neurosurgery for angiography from March 1992 to January 1993. Patients initially underwent clinical evaluation and duplex ultrasound examination at an outpatient cerebrovascular clinic. Those with symptoms of recent carotid territory ischaemic events and duplex ultrasound evidence of greater than $30 \%$ stenosis of the appropriate carotid artery were identified. Those wishing to proceed with further investigations were admitted within two to three weeks for intra-arterial digital subtraction angiography. Informed consent was obtained from patients agreeing to undergo repeat duplex ultrasound examination and magnetic resonance angiography, and all three techniques were then performed during the same hospital admission.

\section{ULTRASOUND TECHNIQUE}

Ultrasound was performed in all cases by the same experienced operator $(\mathrm{PH})$, using both duplex ultrasound examination of the neck (Diasonics C400) and continuous wave probe examination of the neck and orbit (Krahnzbuhler 4 and $8 \mathrm{MHz}$ probe system). The final estimate of percentage stenosis was based on a combination of Doppler flow signal and grey scale image with criteria previously described. ${ }^{10}$

\section{DIGITAL SUBTRACTION ANGIOGRAPHY}

Angiograms were performed under local anaesthetic with selective catheterisation of the common carotid artery via the femoral artery in all except four cases, in which arch angiograms were obtained. Intra-arterial digital subtraction angiograms were obtained with a Siemens digital subtraction unit (Siemens, Angioskop Digitron 2) except in one case where conventional "cut-film" angiograms were obtained with the same equipment. Whenever possible three views-namely, anteroposterior, oblique, and lateral-were obtained. In some cases, if the symptomatic carotid artery was occluded, the contralateral carotid artery was not examined.

\section{MAGNETIC RESONANCE ANGIOGRAPHY}

Magnetic resonance angiography was performed on a $1.5 \mathrm{~T}$ Siemens Magnetom scanner. In one case the patient was positioned in a circularly polarised transmit and receive Siemens head coil. In all other cases a Helmholtz, receive only, Siemens neck coil was used. A short localising sequence to determine the position of the carotid bifurcation and comprising 14 sagittal images through the neck was obtained in all cases. The most suitable image displaying the position of the carotid bifurcation was selected and used to prescribe the other sequences. All but one patient underwent an axial two dimensional time of flight examination of the carotid bifurcation covering a $100 \mathrm{~mm}$ region from the distal common carotid artery to the base of the skull, with 55 axial sections 
(sequence settings; fast low angle shot (FLASH), repetition time $30 \mathrm{~ms}$, echo time 9 $\mathrm{ms}$, flip angle $35^{\circ}, 23 \mathrm{~cm}$ field of view, $192 \times$ 256 matrix, with travelling superior saturation band). Most patients, including the patient in whom the two dimensional sequence was not performed, also underwent an axial three dimensional time of flight examination covering a region 52 to $60 \mathrm{~mm}$ wide around the carotid bifurcation (sequence settings; fast imaging with steady state precession (FISP), repetition time $36 \mathrm{~ms}$, echo time $7 \mathrm{~ms}$, flip angle $15^{\circ}, 64$ partitions, $16 \mathrm{~cm}$ field of view, $192 \times 256$ matrix). Postprocessing of the images obtained was carried out with a maximum intensity projection algorithm. Each carotid bifurcation was processed separately and wherever possible the vertebral arteries were excluded from the processed region. Twelve views at $15^{\circ}$ increments from $0^{\circ}$ to $165^{\circ}$ around each carotid bifurcation were obtained. The time required for a typical examination comprising localising sequence and two and three dimensional time of flight sequences was about 30 minutes, and the time required for postprocessing the images was about 10 minutes.

The duplex ultrasound examinations were performed and interpreted by the same investigator (PH) who was blinded to the results of the other investigations. The $x$ ray and magnetic resonance angiograms were reported independently by one of two consultant neuroradiologists (TN or TS) experienced in interpreting carotid angiograms and blinded from the results of the other investigations. At the end of the study the radiologists reviewed the magnetic resonance and digital subtraction angiograms a second time, so that an assessment of between and within observer variation in reporting could be made. The two and three dimensional magnetic resonance angiograms were viewed together to give a single result for magnetic resonance angiography. The original axial images making up the magnetic resonance angiograms were also available at the time of reporting, if requested. The digital subtraction and magnetic resonance angiograms were then assessed from caliper measurements on two separate occasions by the same investigator (GY). Mechanical calipers reading to $0.1 \mathrm{~mm}$ were used for the digital subtraction films and electronic calipers at the console for the magnetic resonance angiograms. Measurements for each technique were made at separate sittings, with a two week interval to reduce the likelihood of measurements by one method influencing those by the other. The diameter of the minimum residual lumen of the internal carotid artery was used as numerator and the diameter of the common carotid artery lumen just below the bifurcation as denominator to give the percentage residual lumen from which the percentage stenosis was calculated by subtraction from 100 . A vessel showing a "signal gap" by magnetic resonance angiography was arbitrarily assigned a result of $90 \%$ stenosis by caliper, as the residual lumen could not be measured in these circum- stances. For the caliper analysis only, the magnetic resonance viewing angles were limited to those obtained at digital subtraction angiography. This was done because magnetic resonance angiography provides many more views of the bifurcation than are routinely obtainable by digital subtraction angiography. Magnetic resonance angiography could therefore report a tighter stenosis because of a "superior" viewing angle to digital subtraction angiography, rather than because of any inherent difference between the representation of the stenosis by the different techniques. Caliper measurements from magnetic resonance angiograms acquired by the three dimensional technique were used for analysis where possible, with the two dimensional angiograms assessed for those patients undergoing only this examination.

\section{MEASUREMENT OF THE DEGREE OF STENOSIS}

When measuring the degree of stenosis of the carotid artery, the percentage reduction in luminal diameter at the point of maximum stenosis is usually quoted. Often this figure is estimated by simple inspection of the angiogram by a radiologist. Strictly the value should be calculated by measuring the diameter of the original vessel lumen at the point of maximal stenosis, subtracting the diameter of the residual lumen at the same point, and expressing the result as a percentage of the original lumen to give the percentage stenosis. Problems arise because on a conventional angiogram it is not possible to directly measure the original lumen diameter. One solution is to mark on the angiogram the estimated position of the original lumen and make the appropriate measurements, as detailed. This is the method used in the ECST and has the obvious drawback that the result is based on a subjective estimate of where the vessel wall would be. The NASCET used an alternative approach whereby the lumen diameter of the distal internal carotid artery, an area not often affected by atheroma, was used in place of the theoretical original lumen diameter. This has the advantage of being an objective measurement, presumably with less observer variation, but the disadvantage that the result obtained is no longer the percentage reduction in lumen diameter at the point of the stenosis. Other methods have been used including estimates of the cross sectional area stenosis or simply measurement of the residual lumen diameter. We have relied on experienced radiologists reporting their visual impression of the degree of stenosis present, as we believe that this is the method most commonly used in routine clinical practice. The between and within observer variation in reporting with this method may be expected to be greater than when caliper measurements are used. Caliper readings were also taken based on measurements of the diameter of the residual lumen and of the distal common carotid artery as described. The common carotid artery diameter was used as denominator because the distal internal carotid artery was 
Figure 2 Differences between ultrasound (US) and digital subtraction angiography (DSA) measurements plotted for each vessel against the \% stenosis as measured by DSA. For perfect agreement points would all lie along the zero \% difference line.

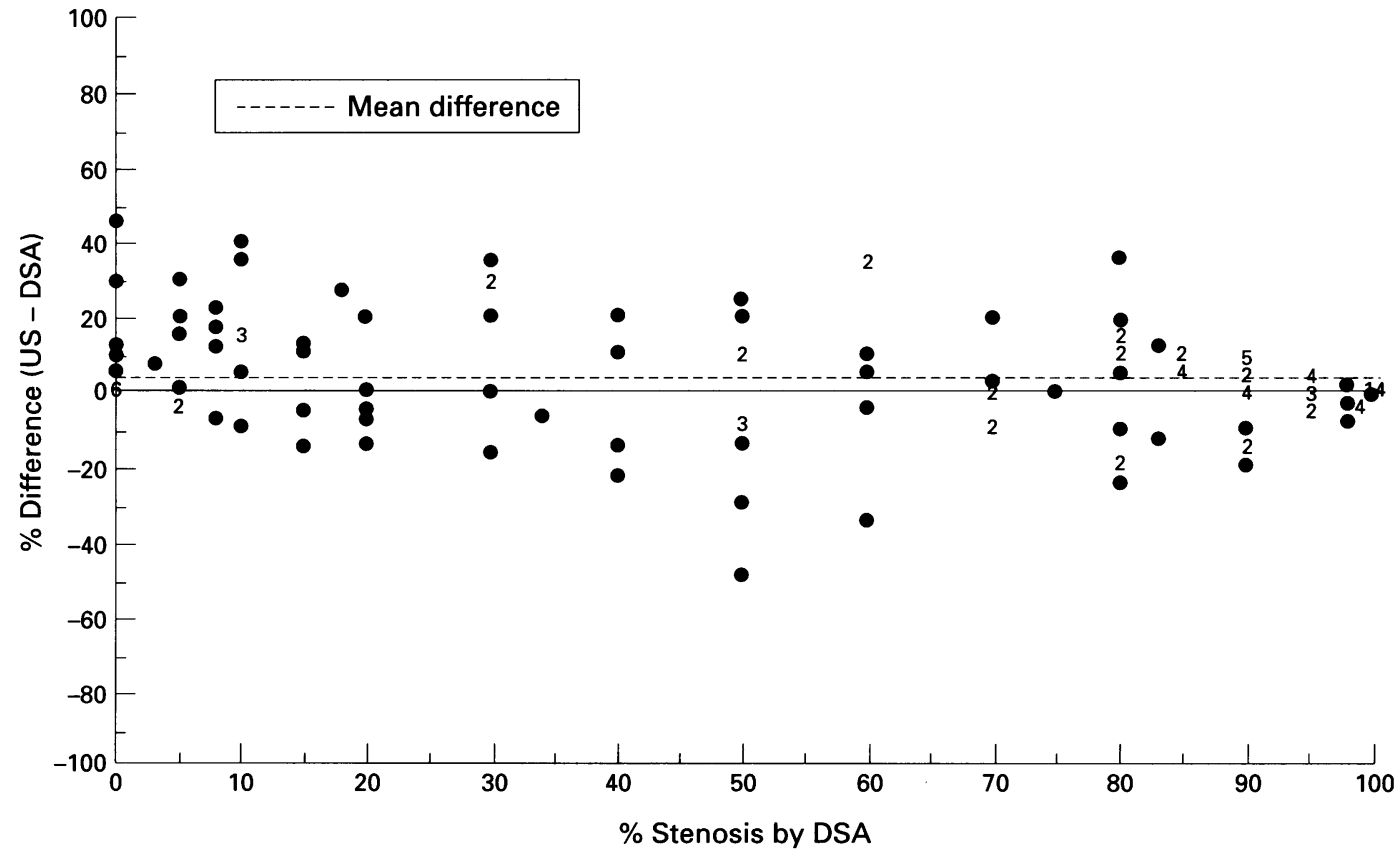

often not included in the three dimensional magnetic resonance angiogram. These results are not therefore percentage reductions in lumen diameter, but are related, assuming a constant relation between the diameter of the common carotid artery and the normal proximal internal carotid artery. There is evidence to suggest a closer relation between the common carotid artery and the carotid bulb than between the distal internal carotid artery and carotid bulb. ${ }^{11}$ Regardless of the relation to the true percentage reduction in diameter, the caliper results enable comparison of magnetic resonance and digital subtraction angiography, because they are objective measurements of the same vessel diameters as displayed by each technique.

STATISTICAL ANALYSIS

Studies that compare one measurement tech-

nique with another are often analysed inappropriately, notably by using correlation coefficients. ${ }^{12}$ Previous studies comparing magnetic resonance angiography with conventional angiography have often quoted high correlation coefficients as an indication of good agreement. ${ }^{13-16}$ The correlation coefficient measures the strength of a relation between two variables, not the agreement between them, and it is possible to produce high correlation coefficients for data that seem to be in poor agreement. ${ }^{12}$ Problems also arise if the data are divided into several groups-for example, mild (0-29\%), moderate (30-69\%), severe $(70-99 \%)$, and occluded $(100 \%)$ categories, with the frequency of assignments to the same category by each method used as a measure of agreement. Results by this technique can be quoted simply as the proportion of assignments in agreement or as the Kappa
Figure 3 Differences between magnetic resonance angiography (MRA) and digital subtraction angiography (DSA) measurements plotted, for each vessel, against the \% stenosis as measured by DSA. For perfect agreement points would all lie along the zero $\%$ difference line.

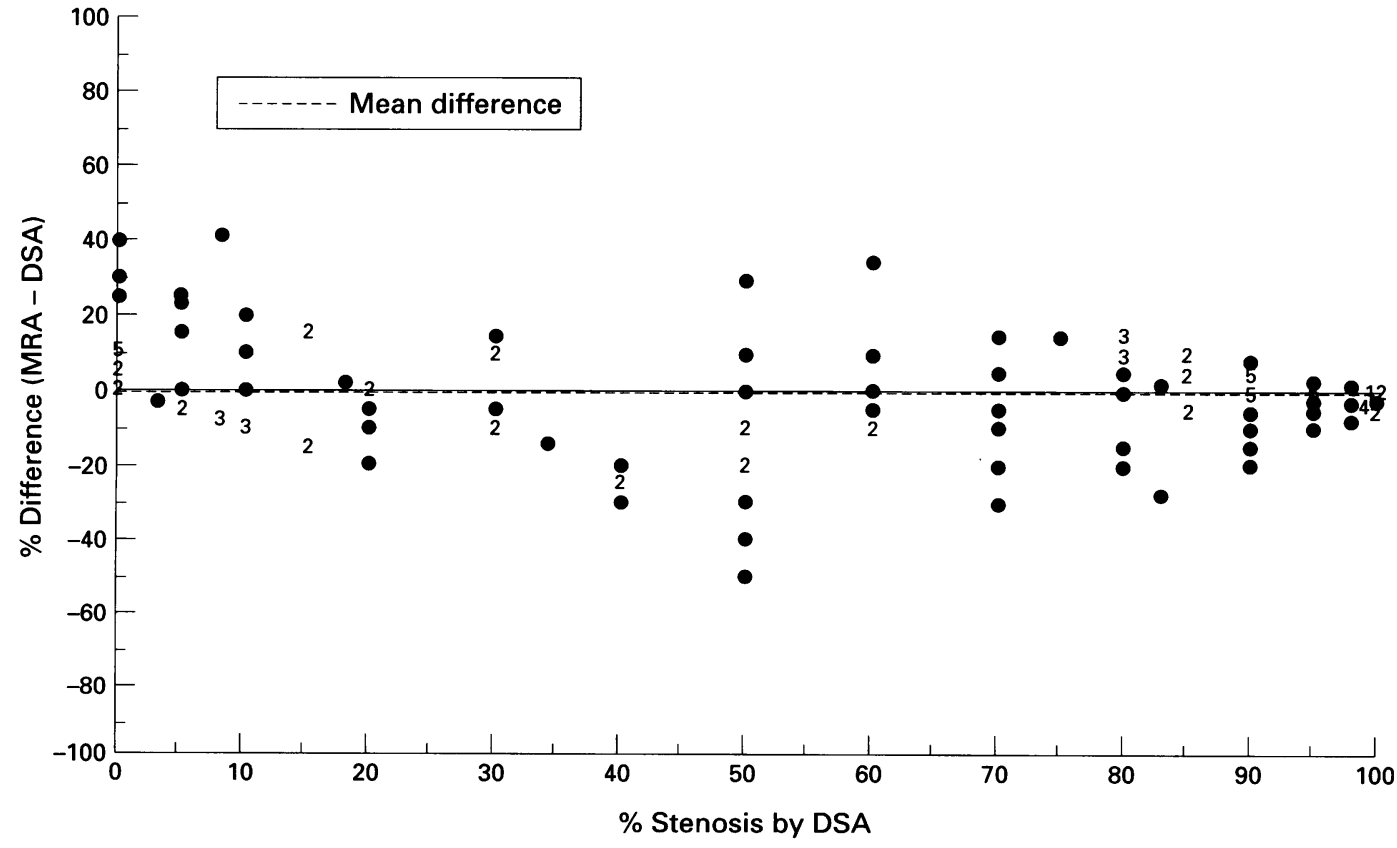


Figure 4 Differences between caliper magnetic resonance angiography (MRA) and caliper digital subtraction angiography (DSA) measurements plotted, for each vessel, against the \% stenosis as measured by the DSA caliper results. For perfect agreement points would all be along the zero \% difference line.

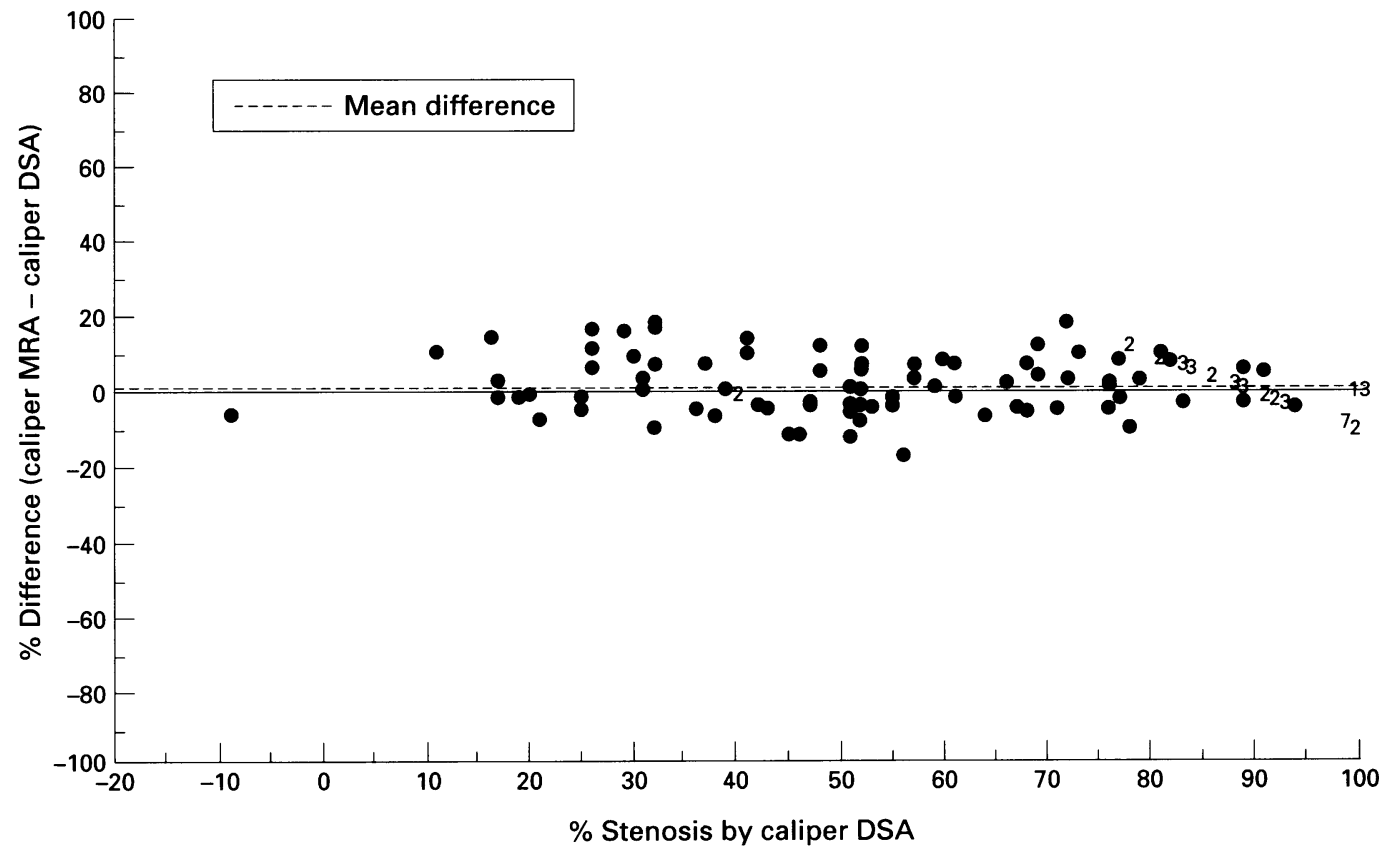

statistic, which corrects for chance agreement. ${ }^{17}$ The results obtained by these techniques will vary according to which arbitrary cut off values are chosen and also according to the number of categories chosen. ${ }^{18}$ The value of a statistic such as Kappa in assessing agreement, particularly of continuous data, is therefore limited. The method described by Bland and Altman and Altman and Bland, which simply takes the differences between the two tests and calculates the mean difference and the SD of the differences is more appropriate. ${ }^{1219}$ The mean difference is an estimate of the average bias of one method relative to another and would be significantly different from zero in the case of one method systematically recording higher or lower values. The SD is a measure of the error between the methods ${ }^{19}$; wide differences between methods and an associated large SD indicates poor agreement. The level of agreement and any relation to the degree of stenosis can be shown by plotting the differences against the means for each pair of test results. ${ }^{12} 19$ Poor agreement would result in a wide scatter of points about the mean difference, whereas any relation between agreement and percentage stenosis would result in a variation in the scatter of points for different values of mean stenosis (figs 2-5). The $95 \%$ limits of agreement, the mean difference $\pm 2 \mathrm{SD}$, has been suggested as the most appropriate way to analyse method comparison data. ${ }^{12}$ As will be seen, when comparing the percentage stenosis measured by different techniques, agreement varies according to the degree of stenosis being measured. This is in part because when results are expressed as percentage stenosis, the maximum possible disagreement becomes progressively less at both extremes of mean
Figure 5 Differences between two radiologists (rad 1, rad 2) reporting the same digital subtraction angiogram (DSA) films plotted for each vessel against the \% stenosis by DSA as used in the previous plots.

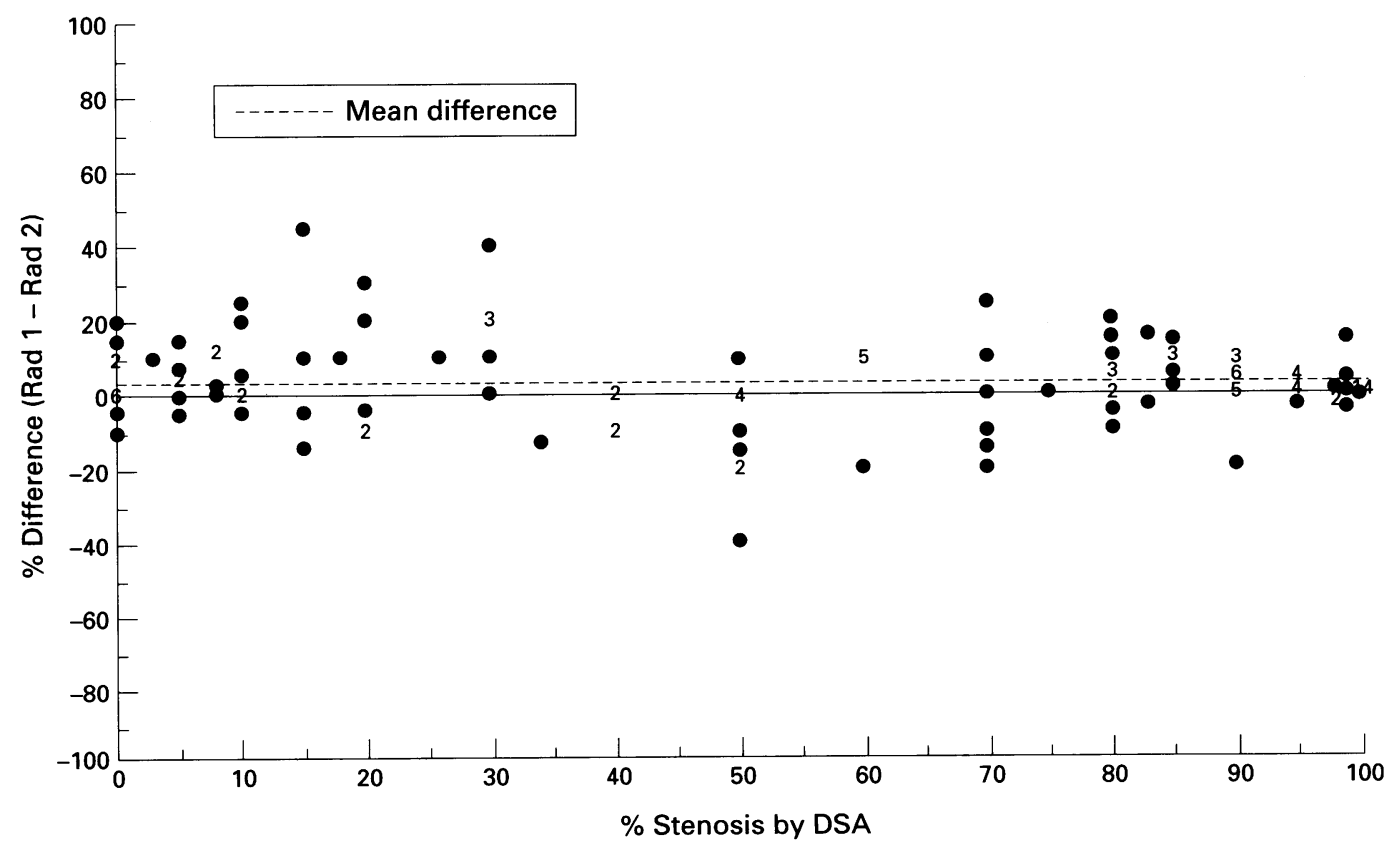


Table 1 Comparison of results by magnetic resonance angiography with those by digital subtraction angiography

\begin{tabular}{lcccc}
\hline \multirow{2}{*}{$\begin{array}{l}\text { Magnetic resonance } \\
\text { angiography (\%) }\end{array}$} & \multicolumn{5}{c}{ Digital subtraction } & angiography (\%) \\
\cline { 2 - 5 } & $0-29$ & $30-69$ & $70-99$ & 100 \\
\hline $0-29$ & 32 & 11 & 0 & 0 \\
$30-69$ & 7 & 13 & 7 & 0 \\
$70-99$ & 0 & 3 & 48 & 3 \\
100 & 0 & 0 & 1 & 12 \\
\hline
\end{tabular}

Values are absolute numbers.

stenosis, so that for a mean result of $0 \%$ or $100 \%$, there can be no difference between the two tests. By plotting the differences between methods against the percentage stenosis as measured by digital subtraction angiography, this effect is eliminated. This approach is not normally recommended because of an artefactual relation between the difference and either of the individual test results. ${ }^{12}$ The relation between agreement and stenosis as measured by digital subtraction angiography, however, is extremely important, as our current criteria for management decisions are based on the results of ECST and NASCET, and therefore on $x$ ray angiography. We have calculated the mean difference (SD), which gives an indication of the agreement on average, across the full range of stenosis values. The closer the mean difference to zero and the smaller the SD of the differences, the better the agreement. An idea of the specific agreement present at different degrees of stenosis can be gained from inspection of the plots of differences against percentage stenosis measured by digital subtraction angiography.

As well as measuring the agreement between different methods of measurement we also wish to describe the ability of the test to diagnose the actual degree of stenosis. The accepted "gold standard" in this context is intra-arterial $x$ ray angiography although this technique has its own limitations. Any new method must be calibrated against the results of $x$ ray angiography, especially as the ECST and NASCET studies are based on results from the technique. Therefore, the sensitivity, specificity, positive predictive, and negative predictive values for ultrasound and magnetic resonance angiography have been calculated at three clinically important cut off valuesnamely, $30 \%, 70 \%$, and $100 \%$ stenosis-with the assumption that the results of digital subtraction angiography represent the true situation. The relation between the caliper index, based on residual lumen and common carotid artery measurements, and the visual impression of stenosis was assessed by linear regression and Pearson's product moment correlation.

Table 2 Comparison of results by ultrasound with those by digital subtraction angiography

\begin{tabular}{lcccc}
\hline & \multicolumn{4}{c}{ Digital subtraction } \\
\cline { 2 - 5 } Ultrasound (\%) & $0-29$ & $30-69$ & $70-99$ & 100 \\
\hline $0-29$ & 32 & 7 & 0 & 0 \\
$30-69$ & 7 & 15 & 5 & 0 \\
$70-99$ & 0 & 5 & 50 & 1 \\
100 & 0 & 0 & 1 & 14 \\
\hline
\end{tabular}

Values are absolute numbers.
Table 3 Mean differences (SD) for digital subtraction angiography (DSA), magnetic resonance angiography (MRA), and ultrasound (US)

\begin{tabular}{lcc}
\hline Comparison & $\begin{array}{l}\text { Mean difference } \\
\%(95 \% \mathrm{CI})\end{array}$ & $S D(\%)$ \\
\hline MRA-DSA & $-0 \cdot 7(-3 \cdot 1$ to $1 \cdot 7)$ & 14 \\
US-DSA & $3 \cdot 1(0.6$ to $5 \cdot 6)$ & 15 \\
MRA-US & $-3 \cdot 8(-6.3$ to $-1 \cdot 2)$ & 15 \\
Caliper (MRA-DSA) & $0.9(-0.3$ to $2 \cdot 2)$ & 7 \\
\hline
\end{tabular}

\section{Results}

During the period of the study 83 patients were referred for angiography. Of these, 79 $(95 \%)$ agreed to take part in the study. In two patients $(3 \%)$ it was not possible to selectively catheterise the common carotid arteries and five patients $(6 \%)$ were unable to complete magnetic resonance angiography. The reasons were claustrophobia in two patients, development of chest pain in one patient with ischaemic heart disease, severe back pain in a patient with chronic back pain, and one patient being too large to fit in the tunnel of the scanner. One digital subtraction angiogram and one magnetic resonance angiogram were considered uninterpretable and were excluded from the analysis. This left 70 patients and a total of 137 vessels examined by all three techniques. There were 49 men and 21 women with a mean age of 62 (range 37-76) years. Presenting symptoms were of recent, non-disabling stroke or transient ischaemic attack in the carotid artery territory in all cases. There were 26 patients with stroke $(37 \%), 36$ with transient ischaemic attack $(51 \%)$ and eight $(11 \%)$ with both stroke and transient ischaemic attack. The mean interval between ultrasound and digital subtraction angiography was $1 \cdot 2$ (range 0-8) days with $96 \%$ performed within two days. The mean interval between magnetic resonance angiography and digital subtraction angiography was 1.3 (range $0-8$ ) days with $92 \%$ performed within two days of each other. A total of 69 of 70 patients and 135 of 137 vessels (99\%) underwent two dimensional and 55 of 70 patients and 107 of 137 vessels $(78 \%)$ three dimensional magnetic resonance angiography.

Tables 1 and 2 show the results for the comparisons between magnetic resonance angiography and ultrasound with digital subtraction angiography, after grouping into mild, moderate, severe, and occluded categories.

The plots of the differences against the

Table 4 Between and within observer variation for digital subtraction angiography (DSA) and magnetic resonance angiography $(M R A)$

\begin{tabular}{|c|c|c|}
\hline & $\begin{array}{l}\text { Mean difference } \\
\%(95 \% \mathrm{CI})\end{array}$ & $S D(\%)$ \\
\hline \multicolumn{3}{|c|}{ Between observer variation } \\
\hline DSA & $2.9(1.0$ to 4.7$)$ & $11 \cdot 2$ \\
\hline MRA & $1 \cdot 1(-0.7$ to 3.0$)$ & $10 \cdot 8$ \\
\hline \multicolumn{3}{|c|}{ Within observer variation } \\
\hline DSA & $2.4(0.9$ to 4.0$)$ & $9 \cdot 0$ \\
\hline MRA & $4 \cdot 0(2.3$ to $5 \cdot 7)$ & $10 \cdot 3$ \\
\hline Caliper DSA & $0.8(0.1$ to 1.4$)$ & 3.9 \\
\hline Caliper MRA & $0.5(-0.6$ to 1.5$)$ & $5 \cdot 7$ \\
\hline
\end{tabular}


Table 5 Sensitivity, specificity, and positive and negative predictive values for ultrasound (US) and magnetic resonance angiography (MRA) at different cut off points, assuming the results of digital subtraction angiography (DSA) to represent the true situation

\begin{tabular}{|c|c|c|c|c|}
\hline Comparison & $\begin{array}{l}\text { Sensitivity } \\
(\%)\end{array}$ & $\begin{array}{l}\text { Specificity } \\
(\%)\end{array}$ & $\begin{array}{l}+ \text { ve predicted } \\
\text { value } \\
(\%)\end{array}$ & $\begin{array}{l}\text {-ve predicted } \\
\text { value } \\
(\%)\end{array}$ \\
\hline \multicolumn{5}{|l|}{ For occlusion } \\
\hline MRA & 80 & 99 & 92 & 98 \\
\hline US & 93 & 99 & 93 & 99 \\
\hline MRA and US* & 92 & 100 & 100 & 99 \\
\hline \multicolumn{5}{|l|}{ For $70-100 \%$ stenosis } \\
\hline MRA & 90 & 95 & 96 & 90 \\
\hline US & 93 & 92 & 93 & 92 \\
\hline MRA and US* & 94 & 95 & 95 & 94 \\
\hline \multicolumn{5}{|l|}{ For $30-100 \%$ stenosis } \\
\hline MRA & 89 & 82 & 93 & 74 \\
\hline US & 93 & 82 & 93 & 82 \\
\hline MRA and US* & 93 & 96 & 99 & 81 \\
\hline \multicolumn{5}{|l|}{ For $70-99 \%$ stenosis } \\
\hline MRA & 86 & 93 & 89 & 90 \\
\hline US & 89 & 93 & 89 & 93 \\
\hline MRA and US ${ }^{\star}$ & 92 & 95 & 92 & 95 \\
\hline
\end{tabular}

*When in agreement (see text). able differences in the assessment of degrees of stenosis for some patients with mild to moderate stenosis, in part related to interobserver variation in reporting. Based on digital subtraction angiography as the gold standard, non-invasive imaging will reliably identify those patients with tight (70-99\%) stenosis.

The mean differences between the different techniques were close to zero, indicating that all three methods agreed closely on average, although sizeable differences occurred between patients (figs 2-4). When comparing digital subtraction angiography and magnetic resonance angiography the $95 \%$ confidence interval for the mean difference included zero, indicating no statistically significant bias. This was not the case when comparing ultrasound with either digital subtraction angiography or magnetic resonance angiography, indicating that ultrasound was recording slightly tighter degrees of stenosis, on average, than the other two modalities. The SDs of the differences between each pair of modalities, an estimate of the error between methods, were similar, indicating similar levels of agreement between each pair of modalities. When comparing the results measured by caliper the mean difference was again close to zero whereas the SD of the differences was considerably less. Thus measuring the same diameters of vessels from the same viewing angle with calipers gave better agreement than recording the visual impression of the percentage stenosis. The caliper measurements, based on the diameter of the common carotid artery some distance away from the point of maximum stenosis, did not actually measure the percentage stenosis, although there was a strong correlation between the two. The results of between and within observer comparisons show similar levels of variation in the radiologists' reporting of digital subtraction and magnetic resonance angiograms. The caliper measurements again show less variation, although an important part of this analysis, namely between observer variation in caliper measurements, has not been performed. These results suggest that a considerable component to the disagreement between different methods is due to between and within observer variation in reporting. The application of quantitative computer techniques to aid lumen border definition, developed particularly for the analysis of coronary arteriograms, ${ }^{20}$ could reduce this problem in carotid angiography.

The sensitivity, specificity, and positive and negative predictive values calculated describe the ability of magnetic resonance angiography or ultrasound to diagnose the percentage stenosis as measured by digital subtraction angiography, which we consider to represent the "true patient status". In fact, it is most unlikely that digital subtraction angiography perfectly describes the true situation in all cases, particularly given the variation in reporting that this and other studies have shown. ${ }^{21-24}$ The criteria currently shown to identify which patients with cerebrovascular disease should proceed to carotid endarterectomy are, however, based on the percentage
The results show good agreement between all three techniques when assessing severe carotid artery stenoses. There are some size- 
Figure 6 (A) Intraarterial digital subtraction angiogram showing tight

stenosis of proximal

internal carotid artery. (B)

Two dimensional magnetic resonance angiogram with

"signal gap" in the region of stenosis. (C) Three

dimensional magnetic

resonance angiogram of the

same vessel showed

superior signal from region of stenosis.
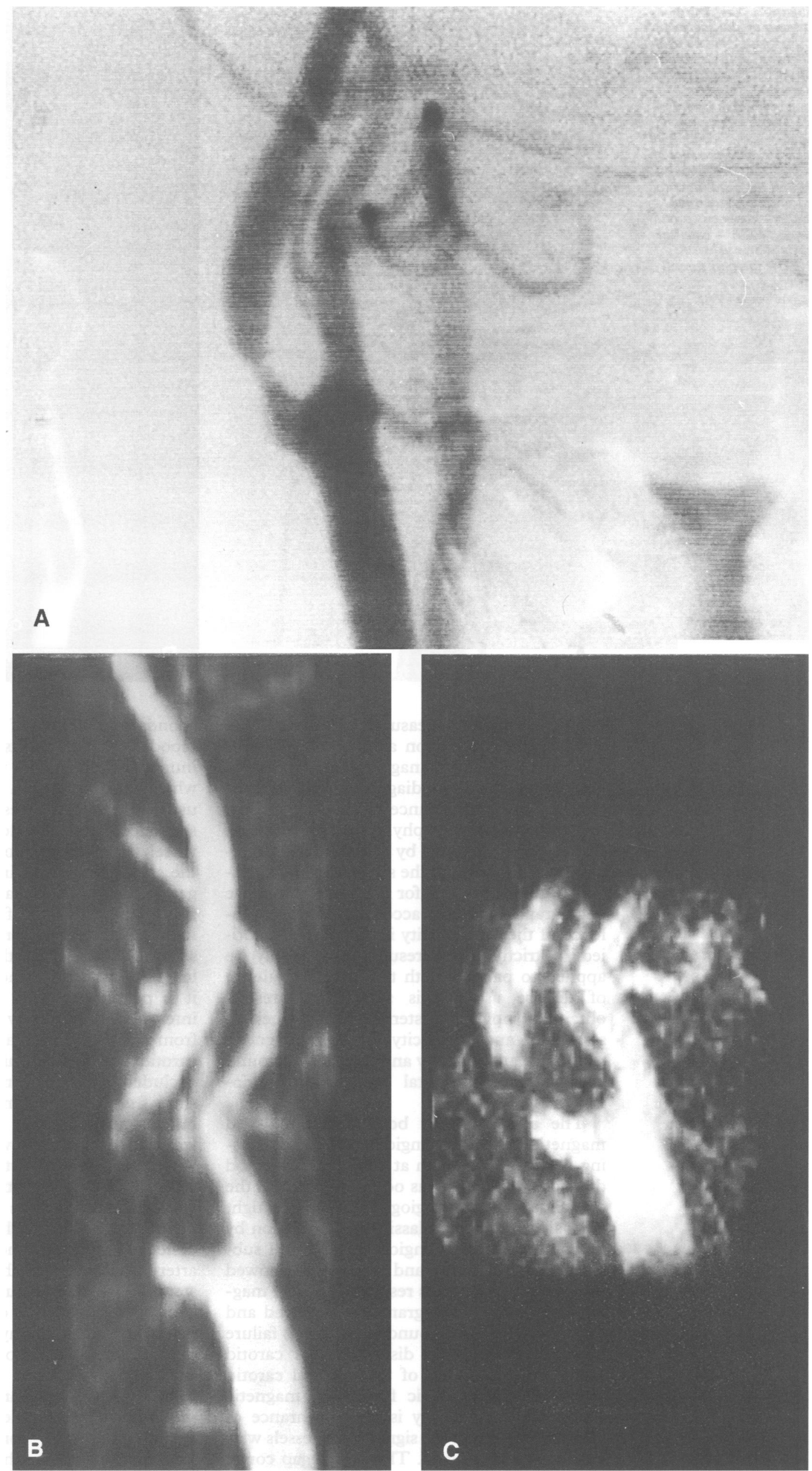
Figure 7 (A) Intraarterial digital subtraction angiogram reported as showing complete occlusion of internal carotid artery (arrow). (B) Two dimensional magnetic resonance angiogram of the same vessel showing tight stenosis, with presence of signal gap, and flow within the distal internal carotid artery (arrow). $C C A=$ common carotid artery; $E C A=$ external carotid artery; ICA = internal carotid artery.

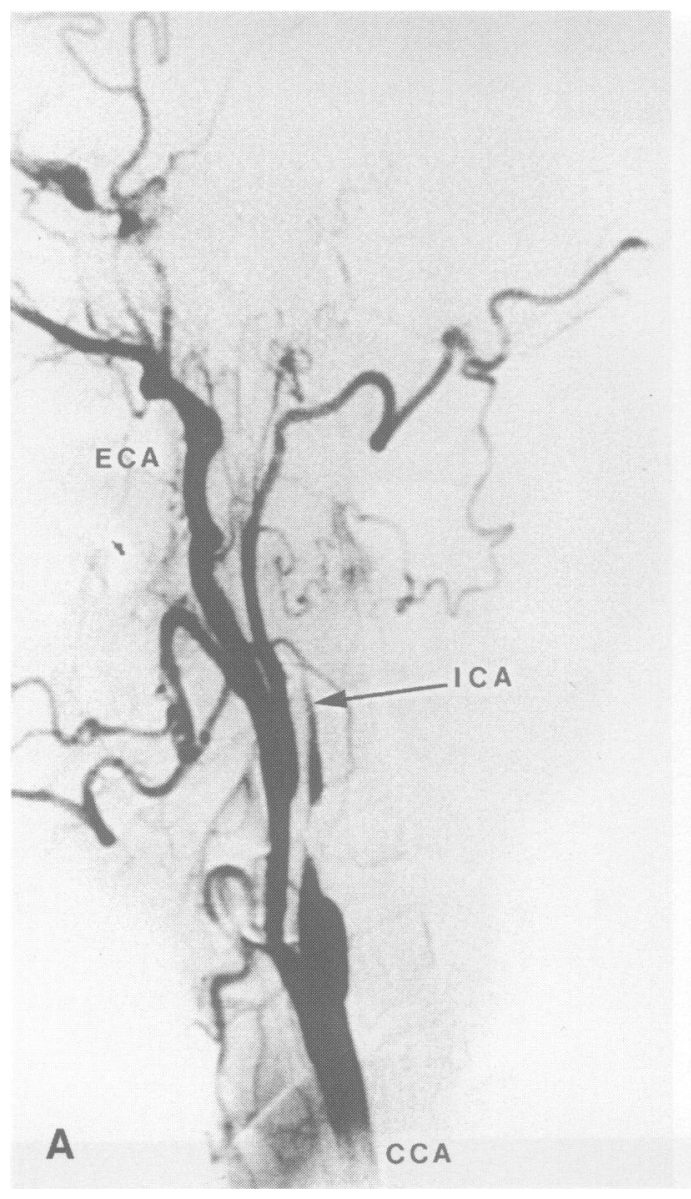

carotid stenosis, as measured by conventional $x$ ray/digital subtraction angiography. Therefore, if we wish to manage patients appropriately by an alternative diagnostic test, we must measure the performance of this test against conventional angiography in the first instance. Because the diagnosis by conventional angiography is not perfect, the sensitivity and specificity values obtained for magnetic resonance angiography will vary according to the prevalence of the abnormality in the patients studied. ${ }^{25}$ Strictly, these results should only be applied to patients with the same prevalence of disease as in this study. The results obtained show consistently high values of sensitivity and specificity for both magnetic resonance angiography and duplex ultrasound compared with digital subtraction angiography.

The specificity for both ultrasound and magnetic resonance angiography in diagnosing occlusion was high at $99 \%$. Each method diagnosed one vessel as occluded whereas the digital subtraction angiogram showed a tight stenosis. In the case classified as occlusion by magnetic resonance angiography, digital subtraction angiography and ultrasound showed $98 \%$ and $95 \%$ stenosis respectively. The magnetic resonance angiogram was reviewed and the misclassification found to be due to failure in distinguishing the distal internal carotid artery from branches of the external carotid artery. A characteristic feature of magnetic resonance angiography is the appearance of an apparent gap in the signal from vessels with a tight stenosis (fig 6). This signal gap corre-

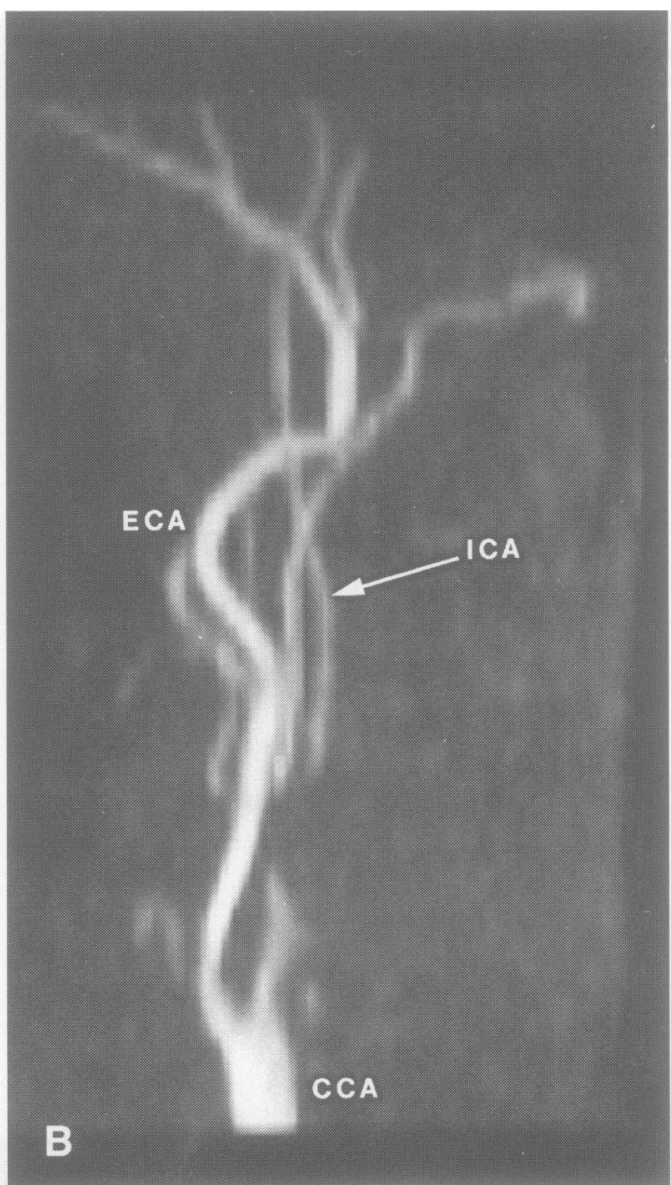

sponds to a region of complex, non-laminar blood flow that exists for a short distance immediately beyond a tight stenosis and from which little signal can be generated with the usual magnetic resonance angiography sequences. Further along the course of the vessel, as uniform blood flow reconstitutes, the signal returns, giving the appearance of a gap in the vessel. Usually it is straightforward to identify the signal from blood flow in the more distal internal carotid artery and to classify the vessel as tightly stenosed. If the full length of the artery is not included in the scan, it is possible to miss signal from the distal internal carotid artery, or to confuse signal from it as being from a branch of the external carotid artery, and misclassify the vessel as occluded. On reviewing the individual axial slices from the two dimensional magnetic resonance angiogram of the particular case, it was evident that there was flow within the distal internal carotid artery, indicating a tight stenosis. We now routinely review individual two dimensional slices through the skull base before diagnosing occlusion, looking for evidence of flow within the distal internal carotid artery. With this method, no cases of tight stenosis by digital subtraction angiography have been classified as occlusions by magnetic resonance angiography. Classification of a tight stenosis as an occlusion, or "pseudoocclusion", has been a recognised problem with duplex ultrasound, ${ }^{26}{ }^{27}$ which can be minimised by supplementing the duplex examination with continuous wave probe examination, and by the use of colour duplex 
sonography. Even with these techniques, some tight stenoses will still be diagnosed as occlusions by ultrasound. ${ }^{28} 29$ The one vessel with ultrasound pseudo-occlusion in this study was recorded as $98 \%$ and $95 \%$ stenosed respectively by digital subtraction angiography and magnetic resonance angiography.

The sensitivity of magnetic resonance angiography in diagnosing occlusion would seem to be low at $80 \%$, with three vessels classified as tightly stenosed by magnetic resonance angiography but as occluded by digital subtraction angiography. On reviewing these cases it was considered that in two instances the magnetic resonance angiogram was correct and that the digital subtraction angiogram had been misreported in one case, and had missed the tight stenosis in the other (fig 7). In this case the magnetic resonance angiogram was straightforward to interpret and ultrasound examination, both before and after digital subtraction angiography, clearly documented a tight stenosis. In the third case, a vessel was reported as tightly stenosed by magnetic resonance angiography and occluded by both digital subtraction angiography and duplex ultrasound. At the end of the study the magnetic resonance angiogram was reviewed, still blinded to the results of other investigations, and was reported as occluded. It is not clear why this vessel was originally misclassified. Overall, particularly when individual axial two dimensional slices through the base of the skull are consulted, we believe that magnetic resonance angiography is highly reliable in detecting occlusion.

For diagnosing stenoses of $70 \%$ or greater, both ultrasound and magnetic resonance angiography perform well. Whatever the method chosen, agreement between the two tests seemed to be better for stenoses $\geqslant 50 \%$ than for stenoses $<50 \%$. This is shown clearly in the plots of the differences against stenosis as measured by digital subtraction angiography (figs 2,3 ), with small differences present in the region of tight stenoses and considerable differences for mild and moderate stenoses. A similar effect was also seen in the assessment of between and within observer variation for both magnetic resonance and digital subtraction angiography (fig 5). In general there is more observer variation, and therefore less agreement, when reporting mild stenoses, a finding noted in other studies. ${ }^{21} 23$ Consequently, both ultrasound and magnetic resonance angiography are less sensitive and specific in diagnosing mild stenosis than digital subtraction angiography. At these levels of stenosis, ultrasound seems closer to the results of conventional angiography.

When only those cases in which the results for ultrasound and magnetic resonance angiography were in agreement are considered, the comparison with digital subtraction is even closer. It has been suggested that it may be possible to make decisions concerning prophylactic carotid endarterectomy with only the results from ultrasound and magnetic resonance angiography, if these are in agreement. ${ }^{30}{ }^{31}$ As the sensitivity and specificity of this combination, measured against conventional angiography, is less than $100 \%$, adopting this approach would result in some patients being referred for operation, and some being treated medically, on the basis of non-invasive tests, when they would have been advised the opposite treatment had conventional angiography been performed. For example, if it is assumed that only vessels classified as having $70 \%$ to $99 \%$ stenosis should be considered suitable for prophylactic carotid endarterectomy then, from these results, magnetic resonance angiography classified 14 vessels $(10 \%)$ differently from digital subtraction angiography (eight as inoperable and six as operable). Ultrasound similarly misclassified 12 vessels $(9 \%)$, six as inoperable and six as operable. Considering just the 127 vessels (93\%) in which ultrasound and magnetic resonance angiography concurred regarding the decision to operate, eight $(6 \%)$ were classified differently by digital subtraction angiography (four as operable and four as inoperable). It is not necessarily a requirement for non-invasive imaging to be perfectly sensitive and specific, because a small loss of accuracy would be offset by the absence of any appreciable risk in comparison with invasive angiography. Furthermore, given the considerable between and within observer variation in the reporting of angiograms that has been documented, it is clear that some patients are already being managed inappropriately on the basis of conventional angiography. With the same criteria for identifying vessels suitable for operation, there were disagreements over 13 vessels $(9 \%)$ concerning suitability for operation when two different radiologists were interpreting the digital subtraction films, and eight disagreements ( $6 \%$ of vessels) when the same radiologist reported the same digital subtraction films on two different occasions. Thus when identifying vessels with $70 \%$ to $99 \%$ stenoses, the number of disagreements between magnetic resonance angiography and digital subtraction angiography (14 vessels) was similar to the number produced by the between observer variation in reporting the digital subtraction angiograms (13 vessels).

Other investigators have reported good results with magnetic resonance, although studies to date have been carried out on different patient populations, with different techniques for conventional angiography, magnetic resonance angiography, and ultrasound examination. The results from most of these studies are based on few patients (less than 50 bifurcations). ${ }^{32-38}$ Others, due to the rapid pace of technological development, are based on magnetic resonance sequences that have since been superseded, ${ }^{39} 40$ and some have inappropriately used correlation to measure agreement. ${ }^{1314}$ Laster et al, in a large series, found excellent agreement between selective contrast angiography and two dimensional time of flight magnetic resonance angiography, when comparing area stenosis by contrast angiography with visual appearance of magnetic resonance angiograms. ${ }^{41}$ As discussed previously, both ECST and 
NASCET used estimates of percentage diameter reduction to assess stenosis. Huston et al, reported $100 \%$ sensitivity and $67 \%$ specificity for two dimensional time of flight magnetic resonance angiography in diagnosing stenoses of $50 \%$ or greater when compared with conventional angiography. ${ }^{42}$ By contrast with our results, they found that the degree of stenosis was consistently overestimated by magnetic resonance angiography.

Wherever possible, the results of both the two dimensional and the three dimensional magnetic resonance angiograms were available to the radiologists. It is not possible therefore, to compare separately the results of the two dimensional and three dimensional techniques with conventional angiography. In general we found the two techniques to be complementary. The two dimensional angiograms covered a wide region around the bifurcation from which it was easy to distinguish the internal and external carotid arteries. This was not always the case when viewing the three dimensional angiograms, which covered a smaller region. Interpretation of the three dimensional magnetic resonance angiogram in this situation required cross reference with the two dimensional magnetic resonance angiogram for correct identification of the internal carotid artery. The contrast between flowing blood and stationary tissue in the two dimensional scan was generally high, even in cases of slow flow, a situation in which vessels were poorly visualised by the three dimensional technique. The three dimensional technique provided higher resolution of the region of stenosis and gave higher signal from the complex flow beyond a tight stenosis than the two dimensional technique.

There are some problems with magnetic resonance angiography. Some patients simply cannot be scanned, such as those with pacemakers or severe claustrophobia. In this study five patients $(6 \%)$ could not complete scans, two (3\%) because of claustrophobia, although this may have been a factor in five patients declining to take part in the study. Occasionally the results obtained are uninterpretable, most commonly because of excessive patient motion. It is possible to place the imaging slices or volume in such a position as to miss the carotid artery bifurcation. In our experience this is usually due to poor visualisation of the bifurcation on sagittal localising images. We now use a series of axial two dimensional magnetic resonance angiogram slices covering the region from shoulder to skull base as localising images, from which it is relatively simple to locate the bifurcation and accurately position the full angiogram sequences. We do not routinely obtain views of the origin of the vessels from the aortic arch, and although such scans can be obtained, information concerning the accuracy of magnetic resonance angiography in this area is currently lacking. We routinely obtain views of the carotid siphon, although imaging in this area poses technical difficulties for magnetic resonance angiography and data concerning accuracy in this region is again lacking. Although there is some debate surrounding this particular problem, ${ }^{4344}$ in our experience relevant siphon stenosis is not a common occurrence and rarely affects the decision to operate; a view for which there is increasing evidence. ${ }^{45}$ Artifacts peculiar to magnetic resonance angiography are encountered, such as the signal gap occurring beyond a tight stenosis. As mentioned previously we have found this useful as it indicates the presence of a tight stenosis and others have even suggested that this appearance could be used to identify patients for endarterectomy without the need for any other preoperative studies. ${ }^{47}$ In this study there were 42 vessels with a signal gap present on two dimensional magnetic resonance angiography. All of these vessels were assigned to the severe stenosis category $(70-99 \%)$ by digital subtraction angiography. Apparent signal gaps can occur with the two dimensional magnetic resonance angiogram techniques utilising a travelling saturation slice. This most commonly occurs when there is a loop in the artery, and creates a peculiar discontinuity in the apparent course of the vessel. It results from arterial blood travelling in the opposite direction to normal in the neck - that is, towards the feet-and in so doing passing through a region of radiofrequency pulses positioned superiorly to the imaging slice for the purpose of preventing signal generation from venous blood. The loop can, however, be visualised quite clearly with a three dimensional technique. A combination of reversed flow and non-laminar flow can occur in the normal carotid bulb giving rise to apparent flattening of the bulb on magnetic resonance angiograms, more pronounced with the two dimensional technique. If this is not appreciated there will be a tendency to classify normal arteries as mildly stenosed. Apparent discontinuities can also occur if the patient moves appreciably during the acquisition of the two dimensional angiogram. This is easy to identify and unless the slice being imaged at the time of motion is in a critical position, such as at the stenosis, it is not usually a serious problem. A recently formed thrombus can generate quite high signals to the extent that it may show on the processed magnetic resonance angiogram. This could theoretically be mistaken for blood flow, although the signal from thrombus has a different quality, which can be recognised with experience. The post-processing technique of maximum intensity projection used to convert the original axial sections into a projection angiogram results in some loss of the lower intensity features of vessels, which can lead to apparent reduction in vessel diameter, overestimation of blood turbulence or stenosis, and poor visualisation of small vessels or vessels with slow flow. ${ }^{48}$

An important finding from this and other studies is that duplex ultrasound may be more accurate overall than magnetic resonance angiography. ${ }^{32} 35$ Several authors have suggested that decisions about operation could be made on the basis of ultrasound assessment alone. $^{3-6}$ The benefit of including magnetic 
resonance angiography is that in some cases it will be superior to ultrasound, as in demonstrating slow flow beyond a very tight stenosis. Also the full extent of the carotid system can be displayed from origin to carotid siphon and intracranial vessels, with the bifurcation reliably seen in cases where ultrasound has difficulty, such as a behind the angle of the mandible. Finally, magnetic resonance angiography provides a permanent morphological record of the vessels, helpful and reassuring to the surgeon in a way that values such as doppler velocity and frequency shift cannot be.

The technique of examining the extracranial vessels by ultrasound is highly dependent on skill and experience. It is therefore important that the ultrasound examination is performed by an experienced operator.

These results show that at high levels of stenosis, non-invasive techniques of magnetic resonance angiography and duplex ultrasound can categorise vessels in a similar way to digital subtraction angiography, particularly when the non-invasive techniques are themselves in agreement. As the proved criteria for recommending prophylactic carotid endarterectomy are based on identifying those patients with a high degree of stenosis, at present $70 \%$ or more, reliable classification of patients can be made on the basis of non-invasive imaging alone. Our current practice for patients with recent non-disabling carotid territory ischaemic episodes, is to screen all patients by duplex ultrasound and those found to have haemodynamically appreciable internal carotid artery stenosis then proceed to magnetic resonance angiography of the neck and head. If both ultrasound and magnetic resonance examinations show a stenosis of $70 \%$ or more then the patient is referred for prophylactic carotid endarterectomy. If the noninvasive tests are not in agreement or if an adequate examination is not possible then we would recommend digital subtraction angiography. This policy will reduce considerably the number of patients undergoing invasive angiography, particularly those with symptomatic tight stenosis of the internal carotid artery. Such a policy has been assessed in other centres with good results. ${ }^{3031}$ In our unit, the risk of digital subtraction angiography causing severe stroke in patients with significant carotid atherosclerosis is $2 \%$, with a risk for carotid endarterectomy of $3 \%$. The combination of ultrasound and magnetic resonance angiography before operation removes the angiographic risk and represents an important advance in the management of carotid stenosis.

We acknowledge the support of the Stroke Association, the Dunhill Medical Trust, and the Mersey Regional Health Authority in this work.

1 European Carotid Surgery Trialists' Collaborative Group. MRC European Carotid Surgery Trial: interim results for symptomatic patients with severe $(70-99 \%)$ or with mild (0-29\%) carotid stenosis. Lancet 1991;337: $1235-43$

2 North American Symptomatic Carotid Endarterectomy Trial Collaborators. Beneficial effect of carotid endarterectomy in symptomatic patients with high-grade carotid stenosis. N Engl F Med 1991;325:445-53.

3 Wagner WH, Treiman RL, Cossman DV, Foran RF, Levin PM, Cohen JL. The diminishing role of diagnostic arteriography in carotid artery disease: duplex scanning as definitive preoperative study. Ann Vasc Surg 1991;5: as definitiv.

4 Farmilo RW, Scott DJA, Cole SEA, Jeans WD, Horrocks $M$. Role of duplex scanning in the selection of patients
for carotid endarterectomy. Br f Surg 1990;77:388-90.

5 Gertler JP, Cambria RP, Kistler JP, et al. Carotid surgery without arteriography: noninvasive selection of patients. Ann Vasc Surg 1991;5:253-6.

6 Ranaboldo C, Davies J, Chant A. Duplex scanning alone before carotid endarterectomy: a 5-year experience. Eur $\mathcal{F}$ Vasc Surg 1991;5:415-9.

7 Murie JA, Morris PJ. Carotid endarterectomy in Great Britain and Ireland. Br $\mathcal{F}$ Surg 1986;73:867-70

8 Hankey GJ, Warlow CP, Molyneux AJ. Complications of cerebral angiography for patients with mild carotid territory ischaemia being considered for carotid endarterectomy. I Neurol Neurosurg Psychiatry 1990;53: 542-8.

9 Davies $\mathrm{KN}$, Humphrey PR. Complications of cerebral angiography in patients with symptomatic carotid territory ischaemia screened by carotid ultras
Neurol Neurosurg Psychiatry 1993;56:967-72.

10 Humphrey P, Sandercock P, Slattery J. A simple method to improve the accuracy of non-invasive ultrasound in selecting TIA patients for cerebral angiography. $\mathcal{F}$ Neurol Neurosurg Psychiatry 1990;53:966-71.

11 Williams MA, Nicolaides AN. Predicting the normal dimensions of the internal and external carotid arteries from the diameter of the common carotid. Eur $\mathcal{F}$ Vasc Surg 1987;1:91-6.

12 Bland JM, Altman DG. Statistical methods for assessing agreement between two methods of clinical measurement. Lancet 1986;i:307-10.

13 Heiserman JE, Drayer BP, Fram EK, et al. Carotid artery stenosis: clinical efficacy of two-dimensional time-ofstenosis: clinical efficacy of two-dimensional tim

14 Anderson CM, Saloner D, Lee RE, et al. Assessment of carotid artery stenosis by MR angiography: comparison with x-ray angiography and colour-coded Doppler ultrasound. Am ₹ Neuroradiol 1992;13:989-1003.

15 Wilkerson DK, Keller I, Mezrich R, et al. The comparative evaluation of three-dimensional magnetic resonance for carotid artery disease. $\mathcal{F}$ Vasc Surg 1991;14:803-11.

16 Wesbey GE, Bergan J, Moreland SI, et al. Cerebrovascular magnetic resonance angiography: a critical verification. $\mathcal{f}$ Vasc Surg 1992;16:619-32.

17 Cohen J. A coefficient of agreement for nominal scales. Educational and psychological measurement 1960;20: $37-46$.

18 Maclure M, Willett WC. Misinterpretation and misuse of the Kappa statistic. Am $\mathcal{F}$ Epidemiol 1987;126:161-9.

19 Altman DG, Bland JM. Measurement in medicine: the analysis of method comparison studies. The Statistician 1983;32:307-17.

20 Brown BG, Bolson EL, Dodge HT. Quantitative computer techniques for analyzing coronary arteriograms. Prog Cardiovasc Dis 1986;28:403-18.

21 Croft RJ, Ellam LD, Harrison MJG. Accuracy of carotid angiography in the assessment of atheroma of the internal carotid artery. Lancet 1980;i:997-1000.

22 Brown PM, Johnston KW. The difficulty of quantifying the severity of carotid stenosis. Surgery 1982;92:468-73.

23 Murie JA, McKay AJ. Radiographic assessment of the extracranial internal carotid artery. $\mathcal{f}$ Cardiovasc Surg 1986;27:154-7.

24 Chikos PM, Fisher LD, Hirsch JH, Harley JD, Thiele BL, Strandness DE. Observer variability in evaluating extracranial carotid artery stenosis. Stroke 1983;14: 885-92.

25 Altman DG. Practical statistics for medical research. London: Chapman and Hall, 1991

26 Ricotta JJ, Bryan FA, Bond MG, et al. Multicentre validation study of real-time (B-Mode) ultrasound, arteriography, and pathological examination. $\mathcal{f}$ Vasc Surg 1987;6:512-20.

27 Comerota AJ, Cranley J, Katz ML, et al. Real-time Bmode carotid imaging. A three-year multicentre experience. $\mathcal{F}$ Vasc Surg 1984;1:84-95.

28 Mattos MA, Hodgson KJ, Ramsey DE, Barkmeier LD, Sumner DS. Identifying total carotid occlusion with colour flow duplex scanning. Eur $f$ Vasc Surg 1992;6:204-10.

29 Erickson SJ, Mewissen MW, Foley WD, et al. Stenosis of the internal carotid artery: assessment using colour Doppler imaging compared with angiography. $A m f$ Roppler imaging compared

30 Turnipseed WD, Kennell TW, Turski PA, Acher CW, Hoch JR. Combined use of duplex imaging and magnetic resonance angiography for evaluation of patients with symptomatic ipsilateral high-grade carotid stenosis. $\mathcal{F}$ with symptomatic ipsilateral

31 Polak JF, Kalina P, Donaldson MC, O'Leary DH, Whittemore AD, Mannick JA. Carotid endarterectomy: preoperative evaluation of candidates with combined Doppler sonography and MR angiography. Radiology 1993;186:333-8.

32 Polak JF, Bajakian RL, O'Leary DH, Anderson MR Donaldson MC, Jolesz FA. Detection of internal carotid artery stenosis: comparison of MR angiography, colour 
Doppler sonography, and arteriography. Radiology 1992;182:35-40.

33 Wagle WA, Dumoulin CL, Souza SP, Cline HE. 3DFT MR angiography of carotid and basilar arteries. $A m \mathcal{F}$ Neuroradiology 1989;10:911-9.

34 Masaryk TJ, Modic MT, Ruggieri PM, et al. Threedimensional (volume) gradient-echo imaging of the carotid bifurcation: preliminary clinical experience. Radiology 1989;171:801-6.

35 Riles TS, Eidelman EM, Litt AW, et al. Comparison of magnetic resonance angiography, conventional angiography, and duplex scanning. Stroke 1992;23:341-6.

36 Mattle HP, Kent C, Edelman RR, Atkinson DJ, Skillman JJ. Evaluation of the extracranial carotid arteries: correlation of magnetic resonance angiography, and conventional angiography. $尹$ Vasc Surg 1991;13:838-45.

37 Kido DK, Barsotti JB, Rice LZ, et al. Evaluation of the carotid artery bifurcation: comparison of magnetic resonance angiography and digital subtraction arch aortography. Neuroradiology 1991;33:48-51.

38 Furuya $\mathrm{Y}$, Isoda $\mathrm{H}$, Hasegawa $\mathrm{S}$, Takahashi $\mathrm{M}$, Kaneko $M$ Uemura $K$ Magnetic resonance angiography of $M$, Uemura $K$. Magnetic resonance angiography of including their origins: comparison with digital subtraction angiography. Neuroradiology 1992;35:42

39 Kido DK, Panzer R, Szumowski J, et al. Clinical evaluation of stenosis of the carotid bifurcation with magnetic resonance angiographic techniques. Arch Neurol 1991;48:484-9.

40 Litt AW, Eidelman EM, Pinto RS, et al. Diagnosis of carotid artery stenosis: comparison of 2DFT time-of- flight $\mathrm{MR}$ angiography with contrast angiography in $\mathbf{5 0}$ patients. Am ₹ Neuroradiol 1991;12:149-54.

41 Laster Jr. RE, Acker JD, Halford III HH, Nauert TC. Assessment of MR angiography versus arteriography for evaluation of cervical carotid bifurcation disease. $A m g$ Neuroradiol 1993;14:681-8.

42 Huston III J, Lewis BD, Wiebers DO, Meyer FB, Riederer SI, Weaver AL. Carotid artery: prospective blinded comparison of two-dimensional time-of-flight MR comparison of two-dimensional time-of-flight MR angiography with conventional a

43 Masaryk TJ, Obuchowski NA. Noninvasive carotid maging: caveat emptor. Radiology 1993;186:325-8.

44 Polak JF. Noninvasive carotid evaluation: carpe diem. Radiology 1993;186:329-31.

45 Schuler JJ, Flanigan DP, Lim LT, Keifer T, Williams LR, Behrend AJ. The effect of carotid siphon stenosis on stroke rate, death, and relief of symptoms following elective carotid endarterectomy. Surgery 1982;92: 1058-67.

46 Mattos MA, van Bemmelen PS, Hodgson KJ, Barkmeier LD, Ramsey DE, Sumner DS. The influence of carotid siphon stenosis on short- and long-term outcome after carotid endarterectomy. F Vasc Surg 1993;17:902-11.

47 Anson JA, Heiserman JE, Drayer BP, Spetzler RF. Surgical decisions on the basis of magnetic resonance angiography of the carotid ..rteries. Neurosurgery 1993; 32:335-43.

48 Anderson CM, Saloner D, Tsuruda JS, Shapeero LG, Lee $\mathrm{RE}$. Artifacts in maximum-intensity-projection display of MR angiograms. Am $\mathcal{F}$ Radiol 1990;154:623-9.

\section{NEUROLOGY IN LITERATURE}

\section{Essential tremor}

Descriptions of essential tremor in literature have commented more on titubation than movement of the limbs. Thomas Mann was clearly aware of the hereditary nature of the condition. I have not encountered a description recognising the disorder's alcohol responsiveness though no doubt Mrs Gamp would have been delighted to justify her dependence on purely medicinal grounds. George Stephenson might have been tempted to attribute his problem to the frustrations of dealing with Sir Astley Cooper. That eminent surgeon had opposed the London to Birmingham railway as being too threatening to his property at Berkhampsted.

Charles Dickens, 1843-4, Martin Chuzzlewit

Mrs Gamp concluded by drawing her shawl tightly over herself with both hands, and, as usual, referred to Mrs Harris for full corroboration of these particulars. She had that peculiar trembling of the head which, in ladies of her excitable nature, may be taken as a sure indication of their breaking out again very shortly. . .

Elizabeth Gaskell, 1853, Cranford

This effort at concealment was the beginning of the tremulous motion of head and hands which I have seen ever since in Miss Matty.

Samuel Smiles, 1857, The lives of George and Robert Stephenson

Although he had for some time been in delicate health, and his hand shook from nervous affection, he appeared to possess a sound constitution.
George Eliot, 1860, The mill on the Floss

He wears a hare-skin on his chest, and has a trembling in his talk. .

\section{Arnold Bennett, 1911, Hilda Lessways}

"And on Saturday afternoon too, when everybody's abroad!" Sarah Gailey added gloomily, with her involuntary small movements of the head. . ."Oh! my poor dear!" Sarah Gailey moaned feebly, her head bobbing with its unconscious nervous movements.

fames foyce, 1916, A portrait of the artist as a young man

He struck the flags again and tittered while his head trembled with a slight nervous movement.

Thomas Mann, 1924, The magic mountain

It was this posture also which helped to steady an incipient shaking of the head, gave him his look of being sternly reined up, and caused him to support his chin on his neckcloth in the manner so congenial to little Hans Castorp's taste. . . Young Hans Castorp noticed that the ancestral tremor brought on by his illadvised walk continued to trouble him - he found it rather an embarrassment when in the dining-room almost as a regular thing now, his head would begin shaking at table; he found this impossible to prevent and hard to dissemble. He tried various devices to disguise the weakness, for he could not continually support his chin on his collar; he would keep his head in action, turning it to the right and left in conversation, or bear hard against the table with the left forearm when he carried a spoonful of soup to his mouth, and support his head with his hand.

G D PERKIN Regional Neurosciences Centre, 